\title{
The Dilemma in Treatment of hemodialysis patients with catheter-induced right atrial thrombi (CRAT): A case report
}

\author{
ZAHRA ANSARI AVAL ${ }^{1}$, RAMIN BAGHAEI ${ }^{2}$, ISA KHAHESHI ${ }^{1}$, AIDA ALAVI-MOGHADDAM ${ }^{1}$ \\ ${ }^{1}$ Cardiovascular Research Center, Cardiac Surgery Department, Modarres Hospital, \\ Shahid Beheshti University of Medical Sciences, Tehran, Iran \\ ${ }^{2}$ Cardiac Surgery Department, Modarres Hospital, The Faculty of Medicine, \\ Shahid Beheshti University of Medical Sciences, Tehran, Iran
}

\begin{abstract}
Catheter-induced right atrial thrombi (CRAT) is a serious complication of central venous catheterization. Herein we report a case of large hypermobile right atrial thrombi in a 57-year-old man with hemodialysis catheter in the right internal jugular vein.
\end{abstract}

Key words: Atrial thrombi, Catheter induced right atrial thrombi, Hemodialysis catheter, End stage renal disease.

\section{INTRODUCTION}

Right atrial thrombi have been associated with atrial fibrillation, flutter, insertion of intracardiac devices and central venous catheters. Catheter-induced right atrial thrombi (CRAT) is a life threatening complication of central venous catheters. Hemodialysis catheters are frequently used in end stage renal disease (ESRD) patients while waiting for arteriovenous graft (AVG) placement and maturation [1]. In this report, we present a case of large hypermobile right atrial thrombi in a known case of ESRD, with central venous catheter in the right internal jugular vein.

\section{CASE REPORT}

A 57 year old man with ESRD, complaining of progressive exertional dyspnea and dry cough for the last two months, was referred to our center for management of right atrial thrombus. The thrombus was detected on transthoracic echocardiography (TTE) in another hospital. His past medical history was remarkable for diabetes mellitus, hypertension, hyperlipidemia and ESRD. During the last 2 years his renal function deteriorated and hemodialysis had been started 13 months earlier. Hemodialysis was performed using a central venous hemodialysis catheter. His examination was normal except for
2/6 new systolic murmur on the left sternal border and bilateral lower lung crackles. TEE showed one $53 * 9 \mathrm{~mm}$ mass bulging out from the lateral wall of the right atrium, highly suggesting a catheterinduced right atrium thrombi with ejection fraction of $60 \%$ (Figure 1). Electrocardiography (ECG) revealed sinus rhythm with left atrial abnormality. The whole blood count showed leukocytosis and mild anemia. Biochemistry tests revealed renal failure (creatinine $7 \mathrm{mg} / \mathrm{dL}$ ) and high erythrocyte sedimentation rate (ESR) $-36 \mathrm{~mm} / \mathrm{h}$. Due to a possibility of catheter related infection, systemic antibiotherapy was initiated. After cardiovascular surgeon consult, due to the size and hypermobility of the thrombus, removal of the thrombus by surgical operation was decided. Before surgery, a coronary angiography was performed and it revealed a severe three-vessel disease. As a result, right atrial thrombus resection and coronary artery bypass grafting (CABG) were both performed. Gross examination of the operative specimen revealed a large mass with irregular surface (Figure 2). No growth of bacteria was reported from thrombus cultures. Microscopic examination showed an organized thrombus with a fibrin network and confirmed the diagnosis of CRAT. The patient experienced no postoperative complications. He was discharged home after ten days of hospitalization with a plan of life long anticoagulation. Serial TTE was performed 3 days, one and three months following the operation and showed no abnormal findings. 


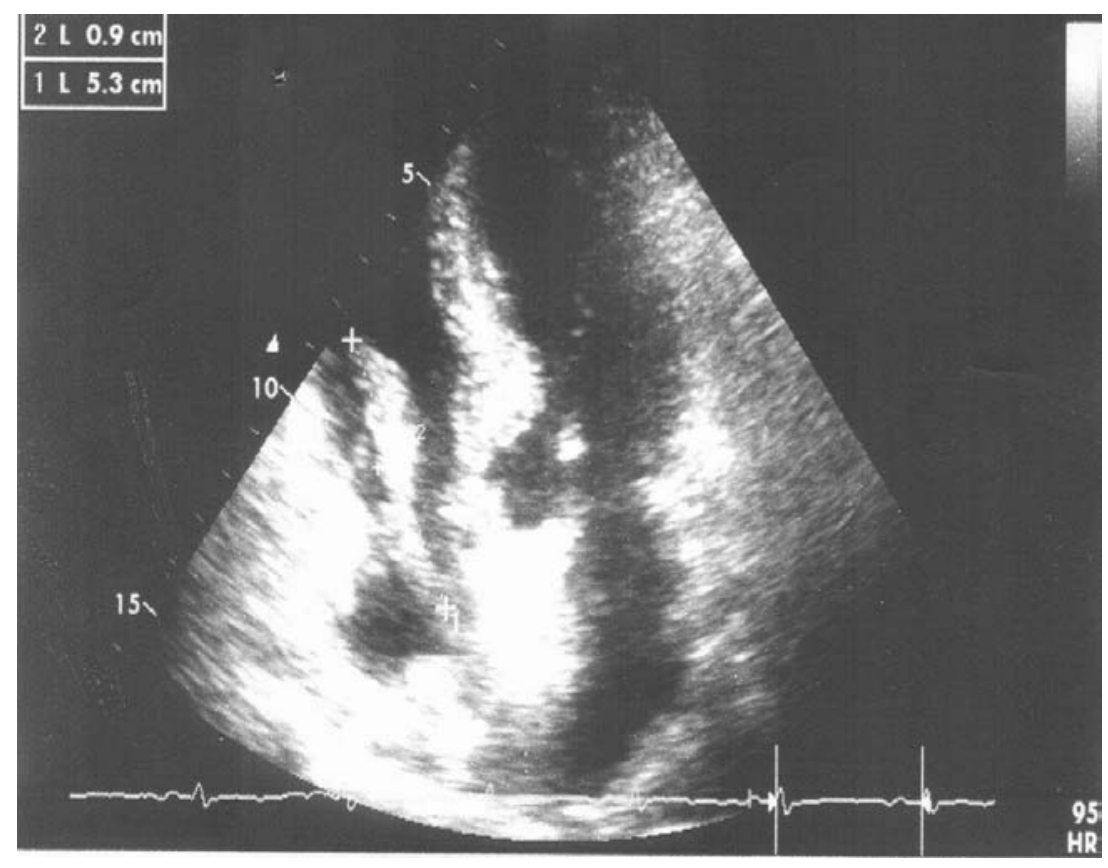

Figure 1. Transthoracic echocardiography showing a large thrombus in the right atrium.

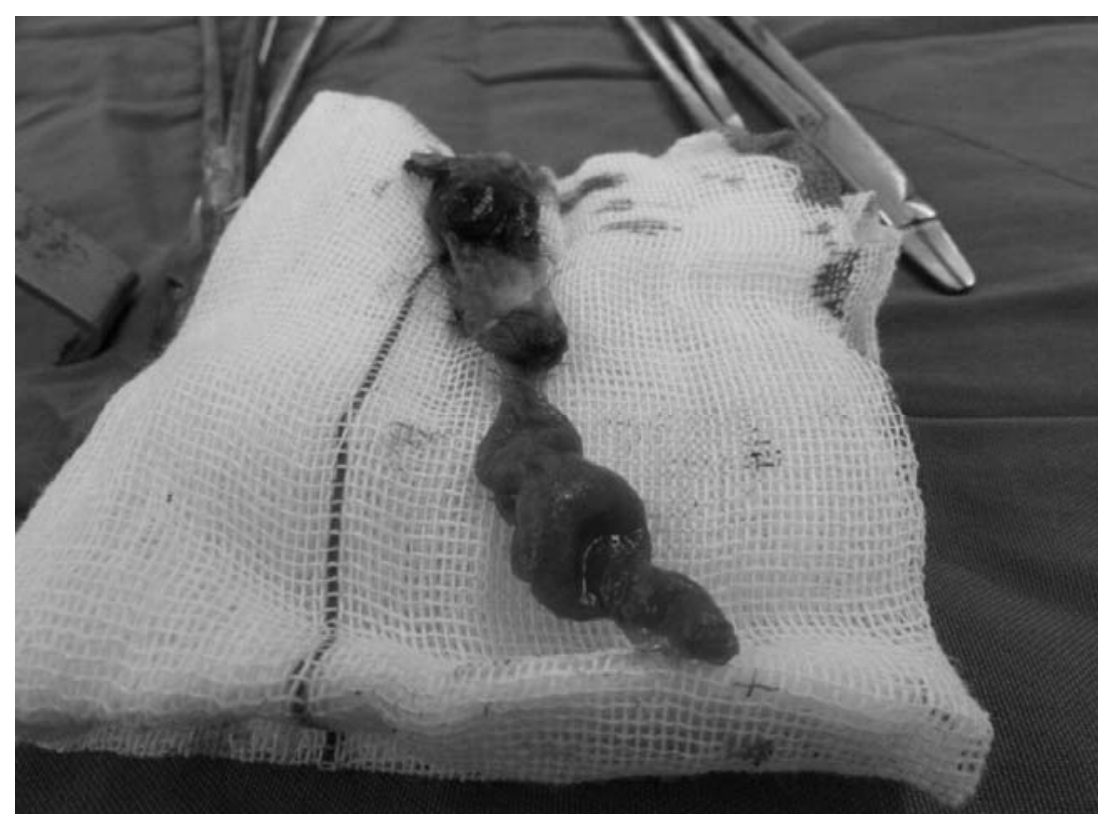

Figure 2. The thrombus removed from the right atrium.

\section{DISCUSSION}

The clinical manifestations of CRAT vary from asymptomatic to life threatening conditions like pulmonary embolism, infection with septic emboli, arrhythmias, hemodynamic compromise or even systemic embolization in cases of a patent foramen ovale. Incidence rate for CRAT is $2-29 \%$ [2]. The overall mortality rate associated with CRAT has been reported to be $18.3 \%$ in hemodialysis patients, (depending on the presence of complications and on non-removal of hemodialysis catheter) and over $40 \%$ in non-hemodialysis patients [3]. According to European working group on echocardiography, there are three types of right atrial thrombi [4]. Type A thrombi are hypermobile and due to deep vein thrombosis (DVT) and/ or pulmonary embolism (PE). Type A has higher mortality rate compared to type B [4]. Type B thrombi are non-mobile and associated with underlying cardiac abnormalities. Type B thrombus forms around foreign bodies 
which were introduced into blood vessels [1], as in our case. Type $\mathrm{C}$ thrombi are highly mobile with morphology similar to myxoma, but they are uncommon. Type A thrombi usually form in peripheral veins while type $B$ thrombi develop inside of the right heart atrium and ventricle [4]. CRAT is an underestimated condition, partly because some patients are asymptomatic on presentation and partly by reason of the TTE limitation in diagnosis of CRAT particularly if catheter tip is proximal in superior vena cava (SVC) [5]. TTE has 50 to $60 \%$ sensitivity for detection of right heart thrombi while TEE has better sensitivity and specificity [5]. The management of right atrial thrombi is a matter of debate among cardiologists. Anticoagulation, surgical removal, thrombolysis and percutaneous intravascular removal of the thrombus are current treatment options [3]. In a meta-analysis that included 71 cases of CRAT in dialysis patients Stavroulopoulos et al. [3] compared current options for management of CRAT. They suggested removal of catheter and anticoagulation as first-line treatment and administration of antibiotics in any cases of bacteremia. According to Stavroulopoulos et al., surgical thrombectomy is recommended whenever other medical treatments fail or in certain situations like contraindications to anticoagulant therapy, concurrent cardiac abnormalities, presence of endocarditis with cardiac surgery indication and if size of thrombus is $\geq 6 \mathrm{~cm}$. However, one case report suggested that thrombi larger than $2 \mathrm{~cm}$ should undergo surgical thrombectomy in the absence of any surgery contraindication [5]. In our case, due to the size and the hypermobility of the thrombus, we postulated that successful rate for medical treatment was low and decided to manage the patient with surgical removal of thrombus. The literature shows that thrombolytic agents could be used in patients in whom anticoagulant therapy failed and/or massive pulmonary embolism developed $[6,7]$. Percutaneous intravascular removal of CRAT may be an option for management of patients in whom anticoagulation is contraindicated and/or surgery is associated with high mortality [8]. Also percutaneous intravascular removal of CRAT could be complementary to surgery when pulmonary arterial thrombi were not surgically removed [9]

\section{CONCLUSION}

In summary, in hemodialysis patients with symptomatic CRAT who have no contraindication for surgery and have large and hypermobile thrombi, surgical thrombectomy is valuable. Percutaneous intravascular removal of CRAT in centers with enough experience may be an alternative option. Lifelong anticoagulant therapy is recommended whenever surgery is contraindicated. Thrombolytic treatment may be life saving in patients with massive pulmonary emboli and without PFO.

However, more sophisticated studies are needed to determine the best option for management of CRAT.

Conflict of interest: The authors agree there is not any conflict of interest in the study to declare.

Trombii formați în atriul drept (CRAT) reprezintă o complicație gravă a cateterismului venos central. Prezentăm cazul unui pacient în vârstă de 57 de ani cu hemodializă şi cateterizat la nivelul venei jugulare drepte interne care a dezvoltat un tromb gigant hipermobil în atriul drept.

Correspondence to: Aida Alavi-Moghaddam, MD

Cardiovascular Research Center, Modarres Hospital, Shahid Beheshti University of Medical Sciences, Tehran, Iran

Tehran, Saadatabad, Kaj Square, Modarres Hospital

Tel: 00989382267248

E-mail: aida.alavi.m@gmail.com

\section{REFERENCES}

1. HUSSAIN N, SHATTUCK P.E., SENUSSI M.H., et al., Large right atrial thrombus associated with central venous catheter requiring open heart surgery. Case Rep Med 2012; 2012:501303.

2. SHAH A., MURRAY M., NZERUE C. M., Right atrial thrombi complicating use of central venous catheters in hemodialysis. International Journal of Artificial Organs 2004; 27(9):772-8. 
3. STAVROUlOPOUlOS A., ARESTI V., ZOUNIS C., Right atrial thrombi complicating haemodialysis catheters. A metaanalysis of reported cases and a proposal of a management algorithm. Nephrology Dialysis Transplantation 2012; 27:2934-44.

4. EUROPEAN WORKING GROUP ON ECHOCARDIOGRAPHY., The European Cooperative Study on the clinical significance of right heart thrombi. Eur Heart J. 1989; 10(12):1046-59.

5. VAN LAECKE S., DHONDT A., DE SUTTER J., VANHOLDER R., Right atrial thrombus in an asymptomatic hemodialysis patient with malfunctioning catheter and patent foramen ovale. Hemodialysis International 2005; 9 (3):236-40.

6. CHARTIER L, BERA J, DELOMEZ M, et al., Free-floating thrombi in the right heart: Diagnosis, management, and prognostic indexes in 38 consecutive patients. Circulation 1999; 99:2779-83.

7. BEREGI JP, AUMEGEAT V, LOUBEYRE C, et al., Right atrial thrombi: percutaneous mechanical thrombectomy. Cardiovasc Intervent Radiol 1997; 20:142-5.

8. TORBICKI A, PERRIER A, KONSTANTINIDES S, et al., Guidelines on the diagnosis and management of acute pulmonary embolism: the Task Force for the Diagnosis and Management of Acute Pulmonary Embolism of the European Society of Cardiology (ESC). EurHeart J 2008; 29:2276-2315.

9. JAFF M.R., MCMURTRY M.S., ARCHER S. L., et al., Management of massive and submassive pulmonary embolism, iliofemoral deep vein thrombosis, and chronic thromboembolic pulmonary hypertension: a scientific statement from the American Heart Association. Circulation 2011; 123 (16):1788-1830.

Received February $3^{\text {rd }}, 2017$ 